\title{
Folic acid Determination in neutral pH electrolyte by Adsorptive Stripping Voltammetry at the Mercury Film Electrode
}

\author{
Pércio Augusto Mardini Farias ${ }^{1}$, Maristela de Castro Rezende ${ }^{1}$, and Josino Costa \\ Moreira $^{2}$ \\ ${ }^{I}$ Departament of Chemistry, Pontificia Universidade Católica, \\ Rua Marquês de São Vicente, 225, CEP 22451-900, Rio de Janeiro, Brazil. \\ ${ }^{2}$ Center for Studies of Workers Health and Human Ecology, \\ Rua Leopoldo Bulhões, 1480, Manguinhos, CEP 21041-210, Rio de Janeiro, Brazil.
}

\begin{abstract}
A stripping method for the determination of folic acid at the submicromolar concentration levels is described. The method is based on controlled adsorptive accumulation of folic acid at the hanging mercury drop electrode followed by differential pulse measurement of the adsorbate. The adsorptive stripping response was evaluated with respect to concentration dependence, accumulation time, accumulation potential, scan-rate, size of the mercury drop, $\mathrm{pH}$, ionic strength, presence of possible interferences and other variables. Cyclic voltammograms at $\mathrm{pH}$ 7.1( $0.2 \mathrm{~mol}^{-\mathrm{L}^{-1}} \mathrm{KH}_{2} \mathrm{PO}_{4} /$ $\mathrm{NaOH}$ buffer solution) showed four cathodic peaks at $-0.57,-0.75,-1.18$ and $-1.39 \mathrm{~V}$. The second peak, (at $-0.75 \mathrm{mV}$ ), was the most useful for analytical purposes (more sensitive, quasi reversible and well defined) and it was used for quantifying folic acid by differential pulse adsorptive stripping voltammetry in four types of pharmaceutical multivitamin preparations. Sequential determination of folic acid with ascorbic acid is also possible. The results obtained in analysing medicines having folic acid as active constituent were compared favourably with those obtained by HPLC with UV detection. The average content of folic acid found in these medicines by HPLC was $4.81 \pm 0.09 \mathrm{mg}$ and by voltammetry, $4.87 \pm 0.09 \mathrm{mg}$. The proposed method is very simple, efficient and does not involve time-consuming separation steps.
\end{abstract}

Keywords- Ascorbic acid, differential pulse voltammetry, folic acid, pharmaceutical preparations, vitamins.

\section{INTRODUCTION}

Folic acid is a water soluble vitamin, initially identified as an anti-anemia and growth factor. It is produced by plants (green leaves, algae) and micro-organisms (bacteria, yeast). In mammals, folic acid and its derivatives, the folates, serve as acceptors and donors of carbon units and are involved in amino acid and nucleotide biosynthesis [1,2]. Folic acid also prevents neural tube defects such as spina bifida, while its ability to lower blood homocysteine concentration, suggests that it might have a positive influence on cardiovascular disease. A role for this B vitamin in maintaining good health may, in fact, extend beyond these clinical conditions to encompass several others disorders (birth defects, several types of cancer, dementia, affective disorders, Down's syndrome etc). Folate is the generic term to indicate a group of compounds naturally occurring in food that have vitamin activity similar to folic acid, such as some polyglutamates. The terms folic acid and folates are often used interchangeably, but folic acid is approximately twice as bioavailable as the folates [3].

Analytical methods for folic acid include bioassays [4], enzymatic methods [5], fluorimetry [6-13], spectrophotometry [14-16], chromatography [17- 25], chemiluminescence [26-28], phosphorimetry [29] and inductively coupled plasmaatomic emission spectroscopy [30]. Electrochemical methods have been used to detect folic acid [31- 42] and to investigate its redox properties [43]. Cathodic adsorptive stripping voltammetry has been used previously to detect low levels of folic acid in different electrolytes and electrodes [44 - 51]. Le Gall and van den Berg used two different buffers with $\mathrm{pH} 5.2$ and 8.5, respectively, and showed the reaction mechanism of folic acid [52].

The present paper describes a differential pulse adsorptive stripping voltammetric method for determination of folic acid in an neutral $\mathrm{pH}$ electrolyte $\left(0.2 \mathrm{~mol} . \mathrm{L}^{-1} \mathrm{KH}_{2} \mathrm{PO}_{4} / \mathrm{NaOH}\right.$ solution ; $\left.\mathrm{pH}=7.1\right)$. Furthermore, we studied the effect of some interference (e.g., copper (II), iron (II), calcium (II) magnesium (II), ascorbic acid, riboflavin and other vitamins). The utility of the method was demonstrated in pharmaceutical formulations including multivitamin preparations. In general, differential pulse adsorptive stripping voltammetry allows good precision and selectivity for determination of drug substances [53-55]. 


\section{EXPERIMENTAL}

\subsection{Apparatus}

The electrochemical experiments (differencial pulse voltammetric) were carried out using a Metrohm 693 VA Processor (5.693.0022) polarograph in conjunction with a VA Stand 694 equipped with three electrodes: a saturated $\mathrm{Ag} / \mathrm{AgCl}$ reference electrode, a hanging mercury drop electrode and a glassy-carbon counter electrode. Cyclic voltammetric studies were carried out using a CV-50W Voltametric Analyser in conjunction with a CGME (Controlled Growth Mercury Electrode) of BAS -Bio Analytical Systems, INC., equipped with three electrodes: a saturated $\mathrm{Ag} / \mathrm{AgCl}$ reference electrode, a hanging mercury drop electrode and a platinum counter electrode.

The HPLC consists of a Shimadzu system (SPD - M10A//SCL - 10A, Kyoto, Japan) with auto sampler, gradient pump, UV detector (diode array detector) and column thermo regulator. Chromatographic separations were performed on a Shimadzu $\mathrm{C}_{18}$ column ( 250 x $4.6 \mathrm{~mm}$ i.d. with packing L1).

\subsection{Reagents and Solutions}

All reagents used were of analytical-reagent grade. Folic acid [N-(4-\{[2-amino-1,4-dihydro-4-oxo-6pteridinyl)methyl]amino\}benzoyl)-L-glutamic acid] was purchased from WHO and it was used without any further purification. Standard solutions of folic acid were prepared daily by dissolving the calculated amount of this vitamin in triply-distilled water. These solutions were kept on dark bottles. The supporting electrolyte was a solution of $\mathrm{pH}=7.1 \mathrm{of}$ phosphate buffer $\left(0.2 \mathrm{~mol} . \mathrm{L}^{-1} \mathrm{NaOH}+\mathrm{KH}_{2} \mathrm{PO}_{4}\right)$. All tested pharmaceutical products were purchased from a local pharmacy.

\subsection{Pharmaceutical Preparations}

The content of folic acid was evaluated in the following pharmaceutical formulations:

(1) Folic acid tablets containing $5.0 \mathrm{mg}$ of folic acid/tablet;

(2) Oral solution containing $0.2 \mathrm{mg} / \mathrm{mL}$ of folic acid associated with ascorbic acid;

(3) Multivitamin effervescent tablets containing $0.2 \mathrm{mg}$ of folic acid/tablet associated with $\mathrm{B}_{1}, \mathrm{~B}_{2}, \mathrm{~B}_{6}, \mathrm{~B}_{12}$ and $\mathrm{E}$ vitamins, nicotinamide, biotin, ascorbic acid, nicotinic acid, calcium and magnesium.

(4) Tablets containing $0.8 \mathrm{mg}$ of folic acid in association with ferric sulphate and ascorbic acid.

\subsection{Sample Preparations}

Tablets: Weigh (to the nearest milligram) 10 tablets and determine the average weight. Pulverize 4 tablets thoroughly in a mortar, and transfer the powder to a dry weighing bottle. Weigh the amount of powder equivalent to one average weight $(0.148 \mathrm{~g}$, in our case $)$ and transfer it into a dry $200-\mathrm{mL}$ volumetric flask. Dissolve in triply-distilled water. Transfer $0.8 \mathrm{~mL}$ of this solution into a $100 \mathrm{~mL}$ volumetric flask and complete with triply-distilled water. Four final solutions were prepared.

Oral solution: The medicine was diluted twice in water, as follows: $0.5 \mathrm{~mL}$ of the pharmaceutical preparation was diluted to $25 \mathrm{~mL}$ and than 0.5 of this dilution was newly diluted to100 $\mathrm{mL}$. Ten final solutions were prepared. Multivitamin tablets: Weigh an amount equivalent to one average tablet weight and transfer it into a dry 1000 -mL volumetric flask. Continue as described for Tablets. Ten final solutions were prepared.

Tablets containing ferrous sulphate: Weigh the amount of powder equivalent to one average weight and transfer it into a dry 500-mL volumetric flask. To a preview masking the iron interference each sample was dissolved with 0.1 mol. $\mathrm{L}^{-1}$ $\mathrm{NaOH}$ solution. If necessary, $0.1 \mathrm{~mol} . \mathrm{L}^{-1} \mathrm{NaOH}$ solutions should be used in any new dilutions. The remaining procedures were exactly as described for Tablets. Four final solutions were prepared.

\subsection{Procedure}

\subsubsection{Differential Pulse Voltammetric}

Ten millilitre $(\mathrm{mL})$ of a $\mathrm{pH}=7.1$ phosphate buffer solution $\left(0.2 \mathrm{~mol} \cdot \mathrm{L}^{-1} \mathrm{NaOH}+\mathrm{KH}_{2} \mathrm{PO}_{4}\right)$ was transferred into the voltammetric cell and degassed with nitrogen for 300 seconds. A pre-concentration potential of $-0.55 \mathrm{~V}$ was applied to the working electrode while the solution was stirred for 120 seconds. For sample analysis, $1 \mathrm{~mL}$ of the final dilution was added into the electrochemical cell containing the support electrolyte prior to degassing step. Other experimental variables were: initial potential $-0.2 \mathrm{~V}$; final potential $-1.2 \mathrm{~V}$, pulse height $50 \mathrm{mV}$ and scan rate $7.5 \mathrm{mv} \cdot \mathrm{s}^{-1}$. All experiments were carried out at the ambient temperature; approximately $24^{\circ} \mathrm{C}$. Purified nitrogen gas was used to eliminate dissolved oxygen. 


\subsubsection{HPLC}

Gradient elution mode was performed with $0.25 \mathrm{~mol} . \mathrm{L}^{-1}$ methanol, $0.5 \mathrm{~mol} . \mathrm{L}^{-1}$ tetrabutylammonium hydroxide and 3.0 mol. $\mathrm{L}^{-1}$ phosphoric acid; with a linearly gradient between $20 \%$ and $50 \%$ of methanol in $10 \mathrm{~min}$ at flow-rate of $1.2 \mathrm{~mL}$. $\min ^{-1}$. The injection volume was $10 \mu \mathrm{L}$. Detection was made at $283 \mathrm{~nm}$.

\section{RESULTS AND DISCUSSION}

\subsection{Parameters Affecting the Adsorptive Stripping Behavior}

Figure 1 shows the adsorptive cyclic voltammograms for $2.26 \times 10^{-6}$ mol. $\mathrm{L}^{-1}$ of folic acid in a $0.2 \mathrm{~mol}^{-\mathrm{L}^{-1}} \mathrm{KH}_{2} \mathrm{PO}_{4} /$ $\mathrm{NaOH}$ solution $(\mathrm{pH}=7.1)$. Other electrolytes such as 1 mol. $\mathrm{L}^{-1} \mathrm{KCl}$ and Britton Robinson at different $\mathrm{pH}(2-10)$ also were utilized; best results were obtained with a 0.2 mol. $\mathrm{L}^{-1} \mathrm{KH}_{2} \mathrm{PO}_{4} / \mathrm{NaOH}$ solution $(\mathrm{pH}=7.1)$. This electrolyte was used throughout this study. Without stirring the solution at $-0.2 \mathrm{~V}$ prior to the scan at $100 \mathrm{mV}$. $\mathrm{s}^{-1}$, result in four cathodic peaks because of reduction steps of folic acid at $-0.57,-0.75,-1.18$ and $-1.39 \mathrm{~V}$. One large and defined peak at -0.75 was selected to a very sensitive electrochemical stripping procedure for folic acid. Also, a smaller and defined peak at $0.73 \mathrm{~V}$ was observed in the anodic branch. The curve dashed represents the blank solution without the presence of folic acid. For this experiment was used a voltammetric analyzer (CV-50W Version 2) of BAS (Bioanalytical Systems, Inc.) with a controlled growth mercury electrode (CGME).

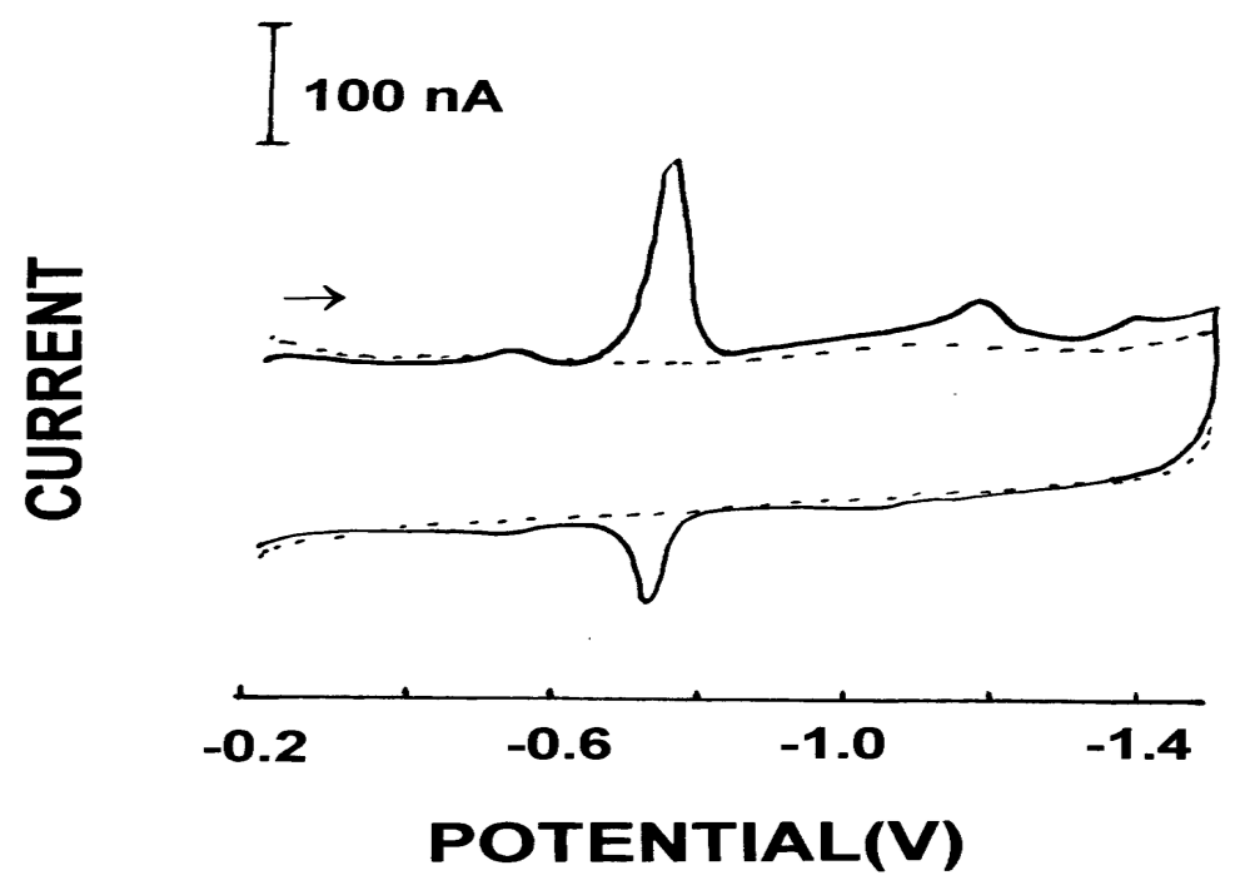

Figure 1. Cyclic stripping voltammograms for $2.26 \times 10^{-6}$ mol. $\mathrm{L}^{-1}$ folic acid in an $0.2 \mathrm{~mol} . \mathrm{L}^{-1} \mathrm{KH}_{2} \mathrm{PO}_{4} / \mathrm{NaOH}$ solution $(\mathrm{pH}=7.1)$. Scan rate, $100 \mathrm{mV} . \mathrm{s}^{-1}$. The dashed curve represents the blank solution. Using a voltammetric analyzer $(\mathrm{CV}$ 50W Version 2) of BAS (Bioanalytical Systems, Inc.) with a controlled growth mercury electrode (CGME).

When the same experiment was repeated at different scan rate, the results of current and potential peak $(\sim-0.75 \mathrm{~V})$ was obtained (Table 1). The plot current peak, $i_{p c}$, versus scan rate, $v$, and potential peak,$E_{p c}$, versus $\log v$ showed a linear variation. The $E_{p c}$ is changed to more negatives values also pointing to a redox process quasi- reversible. A process quasi-reversible also was obtained by Le Gall and van den Berg (1993) when it's analyzed the folic acid in $\mathrm{pH}$ at 8.5. The half-width, $b_{1 / 2}$ for a reversible electrochemical process is $90.6 / \mathrm{n}(\mathrm{mV})$, and for an irreversible process it is $62.5 / \mathrm{an}$ $(\mathrm{mV})$ [56]. Using the equation $b_{1 / 2}=90.6 / n \alpha$ (in $\mathrm{mV}$ ), where ' $\alpha$ ' is the transfer coefficient and ' $n$ ' the number of transferred electrons the following results were obtained. The parameter $\alpha$ is found from the slope of the, $E_{p c}$, versus log $v$ and was close to 0.7. The ' $n$ ' between the electrode and the adsorbed folic acid (at $\mathrm{pH}$ 7.1) during the redox process was calculated approximately as two. This two-electron reduction is in agreement with the reaction mechanism of folic 
acid obtained by same authors [52] at $\mathrm{pH}$ 5.2. No anodic peaks were observed in this $\mathrm{pH}$, indicating that the reduction steps were electrochemically irreversible. In low scan rate $\left(10 \mathrm{mV} . \mathrm{s}^{-1)}\right.$ could be observed a tendency of participation of more electrons in the reaction mechanism of folic acid.

Table 1. Influence of scan rate on the current and potential adsorptive peak (at $\sim-0.75 \mathrm{~V})$ for the folic acid.

\begin{tabular}{lllll}
\hline$\nu, \mathrm{mV}_{\mathrm{s}} \mathrm{s}^{-1}$ & $E_{p c}, \mathrm{mV}$ & $i_{p c}, \mathrm{~A}$ & $b_{1 / 2}$ & $n$ \\
\hline \hline & & & & \\
50 & -745 & $1.9 \times 10^{-8}$ & 35.1 & $\sim 3$ \\
100 & -756 & $1.0 \times 10^{-7}$ & 58.5 & $\sim 2$ \\
500 & -758 & $1.7 \times 10^{-7}$ & 58.5 & $\sim 2$ \\
\hline
\end{tabular}

Conditions: cyclic voltammograms for $2.26 \times 10^{-6}$ mol. $\mathrm{L}^{-1}$ folic acid in an $0.2 \mathrm{~mol} . \mathrm{L}^{-1} \mathrm{KH}_{2} \mathrm{PO} / \mathrm{NaOH}$ solution $(\mathrm{pH}=7.1$ ). Initial potential: $-0.20 \mathrm{~V}$; switch potential: $-1.50 \mathrm{~V}$. Using an voltammetric analyzer (CV-50W Version 2) of BAS (Bioanalytical Systems, Inc.) with a controlled growth mercury electrode(CGME).

The spontaneous adsorption of the folic acid can be used as an effective acumulation step, prior to the voltammetric measurement. In this way, highly sensitive measurements of folic acid can be achieved by means of adsorptive stripping voltammetry. Differential pulse voltammetry is a well known and very sensitive analytical technique for the determination of metal ions, electroactive organic molecules, and many anions (Wang et al. 1985 and 1986; Cardoso et al. 2005). Differential pulse adsorptive stripping voltammogram for $2.7 \times 10^{-7} \mathrm{~mol}^{-1} \mathrm{~L}^{-1}$ folic acid in a $0.2 \mathrm{~mol} . \mathrm{L}^{-1}$ $\mathrm{KH}_{2} \mathrm{PO}_{4} / \mathrm{NaOH}$ solution $(\mathrm{pH}=7.1)$ is shown in Figure 2. Three well defined cathodic peaks can be observed at -0.47 , 0.68 and $-1.08 \mathrm{~V}$. The shape and the sensitivity of the peak at $-0.68 \mathrm{~V}$ make it more adequate and provide the basis for the quantitative determination of folic acid. Similar results were obtained by cyclic voltammetry.

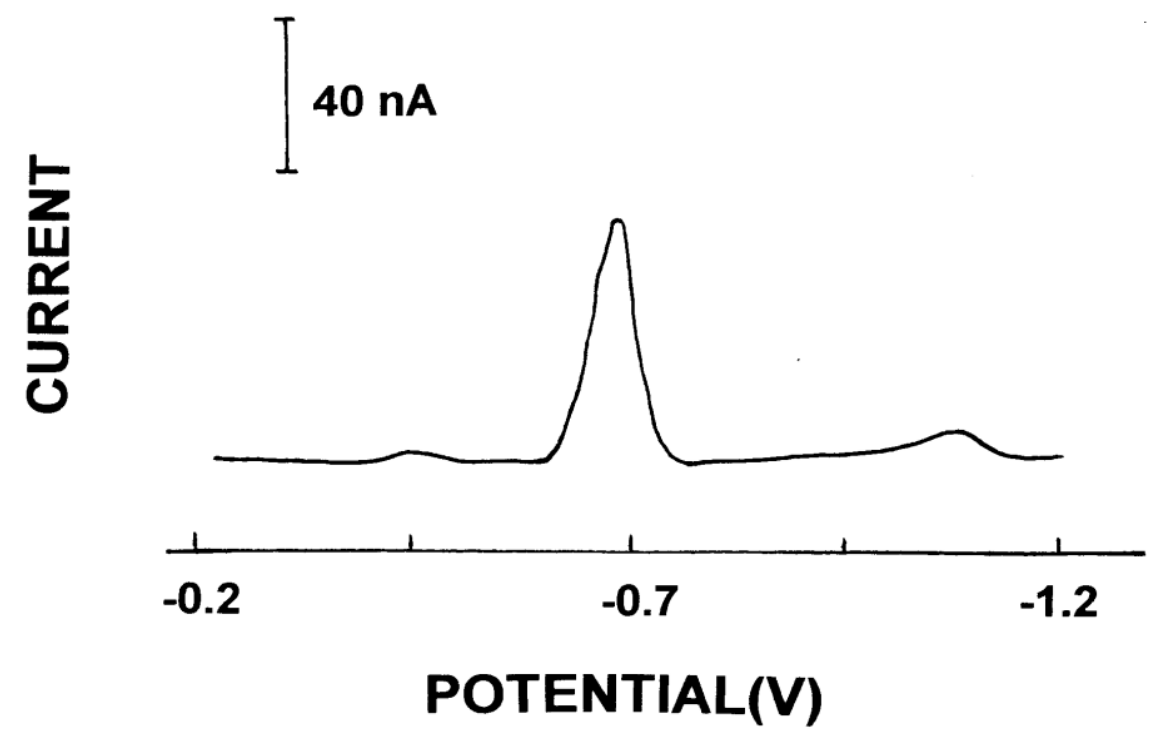

Figure 2. Differential pulse adsorptive stripping voltammograms for $2.7 \times 10^{-7} \mathrm{~mol}^{-\mathrm{L}^{-1}}$ folic acid in a $0.2 \mathrm{~mol} . \mathrm{L}^{-1}$ $\mathrm{KH}_{2} \mathrm{PO}_{4} / \mathrm{NaOH}$ solution ( $\mathrm{pH}=7.1$ ). Accumulation time, 120 s at $-0.2 \mathrm{~V}$ with stirring solution; pulse amplitude, $50 \mathrm{mV}$ and scan rate, $7.5 \mathrm{mV} . \mathrm{s}^{-1}$. 
Figure 3 shows the dependence of the adsorptive stripping peak current on the accumulation time at two folic acid concentration levels ( $9.0 \times 10^{-7}$ and $1.2 \times 10^{-5}$ mol. $\left.\mathrm{L}^{-1}\right)$. At longer accumulation times, more folic acid adsorbs at the HMDE surface and larger peak current is obtained. For both concentrations, the peak current increases linearly with the accumulation time up to $240 \mathrm{~s}$. At $10^{-5} \mathrm{M}$ folic acid concentration, the peak increases at first and then curves toward the time axis. As in all types of stripping measurements, the choice of accumulation time requires a trade-off between sensitivity and speed, times of $480 \mathrm{~s}$ and $120 \mathrm{~s}$, respectively, were selected for quantitative determination of folic acid at the $10^{-8}$ and $10^{-5}$ mol. $\mathrm{L}^{-1}$ levels. It was also observed a perceptible dependence of the stripping currents and potentials peak with the accumulation potential. An accumulation time of $120 \mathrm{~s}$ at $-0.5 \mathrm{~V}$ was used throughout this work as the best compromise between sensitivity and speed.

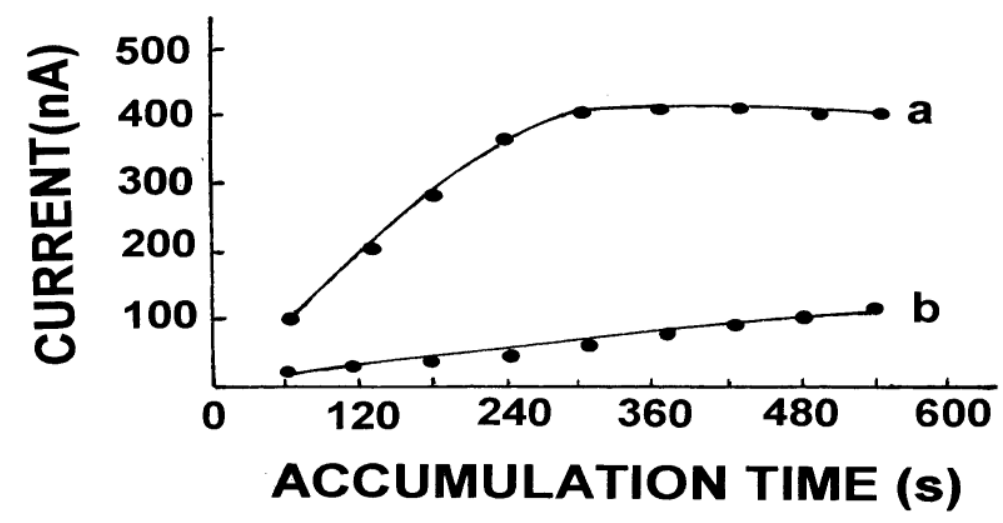

Figure 3. Effects of accumulation time on the differential pulse adsorptive stripping current peak of $1.2 \times 10^{-5}$ (a) and 9.0 $\mathrm{x} 10^{-7}$ (b) mol.L $\mathrm{L}^{-1}$ of folic acid in an $0.2 \mathrm{~mol} . \mathrm{L}^{-1} \mathrm{KH}_{2} \mathrm{PO}_{4} / \mathrm{NaOH}$ solution $(\mathrm{pH}=7.1)$. Accumulation time at $-0.5 \mathrm{~V}$. Scan rate, $7.5 \mathrm{mV} . \mathrm{s}^{-1}$.

Other experimental variables which affecting the adsorptive stripping response were evaluated and optimised. Pulse amplitude, $a$, affects the resulting stripping response. The stripping peak current , $i_{p c}$, and the half-width, $b_{1 / 2}$, at different pulse amplitude are summarized in Table 2. Best results were obtained with $50 \mathrm{mV}$; this pulse amplitude was used throughout this study. A fourfold increase in the peak current is observed on changing the drop size from small to large; these drop sizes correspond to surface area ratio of 1:4. As the potential peak remains essentially the same, the large size is recommended when maximum sensitivity is required. Although the adsorptive stripping response increases with the electrode area, this gain in sensitivity is accompanied by peak broadening. In this work, a drop size of $0.4312 \mathrm{~mm}^{2}$ showed the best compromise when considering the sensitivity and resolution requirements.

Table 2. Dependence of peak current of pulse amplitude.

\begin{tabular}{lll}
\hline$a, \mathrm{mV}$ & $i_{p c}, \mathrm{nA}$ & $b_{1 / 2}, \mathrm{mV}$ \\
\hline \hline 25 & 58.09 & 74.07 \\
50 & 116.53 & 81.48 \\
100 & 198.70 & 88.89 \\
\hline
\end{tabular}

Conditions: differential pulse voltammograms for $6.78 \times 10^{-7}$ mol.L $\mathrm{L}^{-1}$ folic acid in an $0.2 \mathrm{~mol}^{-\mathrm{L}^{-1}} \mathrm{KH}_{2} \mathrm{PO}_{4} / \mathrm{NaOH}$ solution ( $\mathrm{pH}=7.1$ ). Initial potential: $-0.20 \mathrm{~V}$; final potential: $-1.20 \mathrm{~V}$. Scan rate, $7.5 \mathrm{mV}$. $\mathrm{s}^{-1}$ and $0.4312 \mathrm{~mm}^{2}$ as drop size. 


\subsection{Quantitative Utility}

Figure 4A illustrates the stripping current response to successive standard additions of folic acid into the voltammetric cell. Each addition corresponds to a $1.3 \times 10^{-7}$ mol.L $\mathrm{L}^{-1}$ increase in folic acid concentration. The resulting plot of peak current vs. concentration is linear (slope $3.48 \times 10^{-2} \mathrm{~A}$. L/mol; correlation coefficient 0.997 ). Such linearity prevails as long as linear isotherm conditions (low surface coverage) exist. In another similar experiment, solutions of higher concentration $\left(2.0 \times 10^{-6}-1.0 \times 10^{-5}\right.$ mol. $\mathrm{L}^{-1}$; other conditions as figure $\left.4 \mathrm{~A}\right)$ were used. The resulting plot of peak current vs. concentration is also linear (slope $8.11 \times 10^{-3} \mathrm{~A}$. L/mol; correlation coefficient 0.999$)$. A detection limit of $1.4 \times 10^{-8}$ mol. $\mathrm{L}^{-1}$ was estimated from quantitation of $1.26 \times 10^{-7}$ after a 2 -min accumulation $(\mathrm{S} / \mathrm{N}=3)$. It was also evaluated the interference from coexisting metal ions, capable of forming complexes with folic acid or depositing at the mercury electrode. Copper (II) ions at the $7.43 \times 10^{-4}$ mol.L $\mathrm{L}^{-1}$ level do not interfere in the determination of $2.71 \times 10^{-7} \mathrm{~mol} . \mathrm{L}^{-1}$ folic acid. Iron (II) at the $8.44 \times 10^{-5} \mathrm{~mol} \mathrm{~L}^{-1}$ also does not interfere in the determination of $9.04 \times 10^{-4}$ mol. $\mathrm{L}^{-1}$ folic acid.
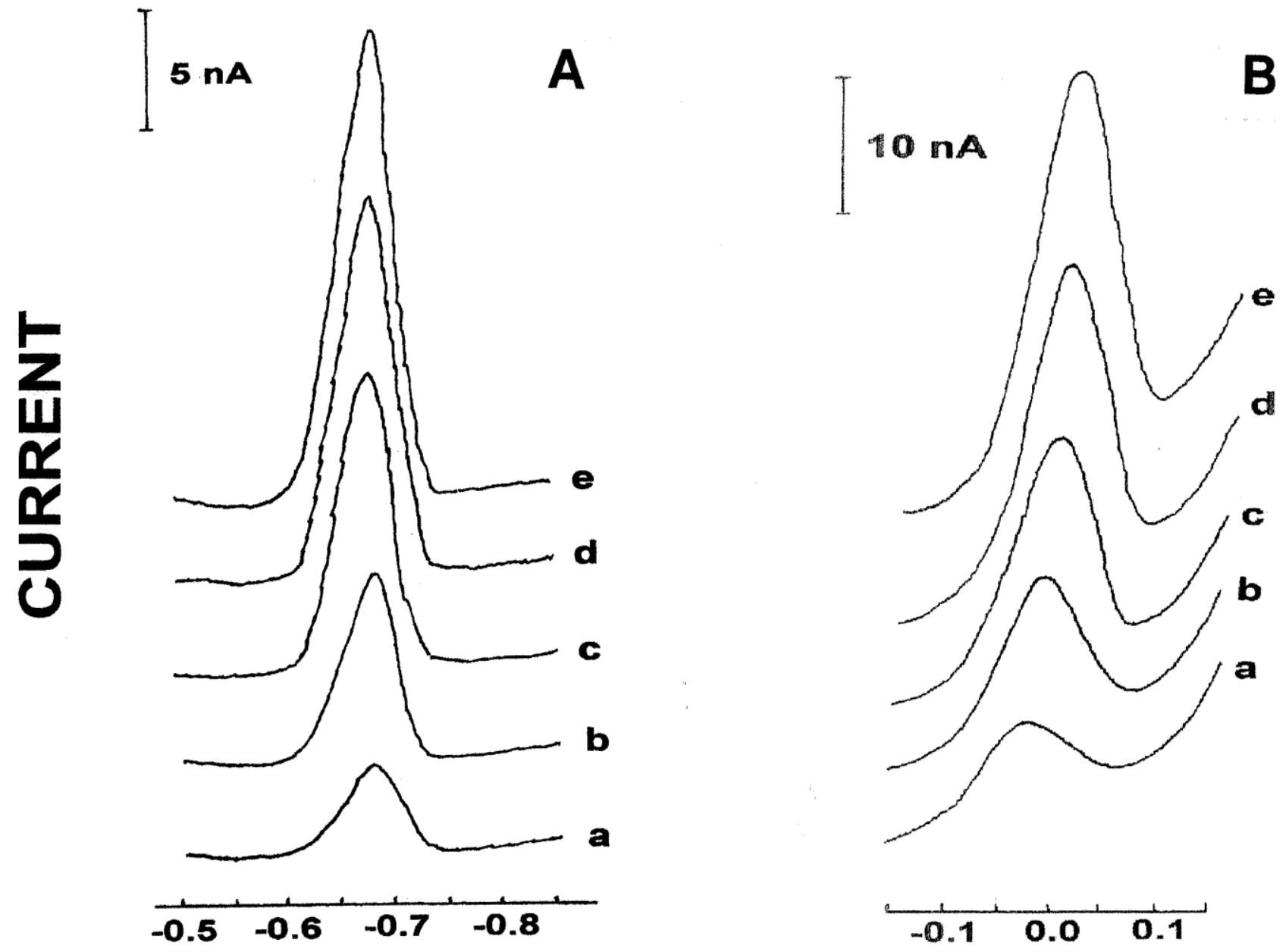

\section{POTENTIAL (V)}

Figure 4. Differential pulse adsorptive stripping voltammograms of folic acid (A) and ascorbic acid (B) in 0.2 mol. $\mathrm{L}^{-1}$ $\mathrm{KH}_{2} \mathrm{PO}_{4} / \mathrm{NaOH}$ solution $\left(\mathrm{pH}=7.1\right.$ ) for increasing folic acid concentrations in $1.3 \times 10^{-7}$ mol.L $\mathrm{L}^{-1}$ steps $(\mathrm{A}$; a-e) and ascorbic acid concentrations in $1.1 \times 10^{-4}$ mol. $\mathrm{L}^{-1}$ steps $\left(\mathrm{B}\right.$; a-e). Scan rate, $7.5 \mathrm{mV}$. $\mathrm{s}^{-1}$; pulse amplitude $50 \mathrm{mV}$. Accumulation time, $120 \mathrm{~s}$ at $-0.5 \mathrm{~V}$, and $0.4312 \mathrm{~mm}^{2}$ as drop size (A). Initial at $-0.15 \mathrm{~V}$ and final potential at $+0.15 \mathrm{~V}$, and $0.3187 \mathrm{~mm}^{2}$ as drop size (B). 
The possible sequential determination of ascorbic acid and folic acid using the same support electrolyte $\left(0.2\right.$ mol. $\mathrm{L}^{-1}$ $\mathrm{KH}_{2} \mathrm{PO}_{4} / \mathrm{NaOH}$ solution ( $\left.\mathrm{pH}=7.1\right)$ ), also was studied. Ascorbic acid can be determined by differential pulse voltammetry by examining the anodic wave due the oxidation of the 'enedial' system. Ascorbic acid is a strong reducing agent and at higher $\mathrm{pH}$ values it will quickly reduce even dissolved oxygen. Therefore, it is preferable to prepare standard ascorbic acid solutions at low $\mathrm{pH}$ values (for example, in the presence of 0.1 mol. $\mathrm{L}^{-1}$ citric acid). Figure 4B shows voltammograms for solutions of increasing ascorbic acid concentration $\left(1.1 \times 10^{-4}-5.7 \times 10^{-4} \mathrm{moles}^{-1} \mathrm{~L}^{-1}\right)$ in $0.2 \mathrm{~mol} . \mathrm{L}^{-1}$ $\mathrm{KH}_{2} \mathrm{PO}_{4} / \mathrm{NaOH}$ solution $(\mathrm{pH}=7.1)$ without accumulation. The resulting plot of peak current vs. concentration is linear (slope $5.02 \times 10^{-5} \mathrm{~A}$. L/mol; correlation coefficient 0.999).

\subsection{Analytical Application in Pharmaceutical Preparations.}

The developed methodology was used to quantify folic acid in several pharmaceutical forms including multivitamin preparations (tablets and oral solution). Simple and complex samples such as multivitamin tablets, nominally containing $1.6 \mathrm{mg}$ of riboflavin, $60 \mathrm{mg}$ of ascorbic acid, $200 \mu \mathrm{g}$ of folic acid, calcium, magnesium, seven other vitamins plus excipients was tested. Ten samples were analysed following the procedure described under experimental. Calibration curve or standard addition methods were used to determine the contents of folic acid present in those samples. The recovery tests of folic acid ranging from $1.26 \times 10^{-7}$ to $6.33 \times 10^{-7} \mathrm{~mol} \mathrm{~L}^{-1}$ were performed. The results obtained are given in Table 3.

Table 3. Folic acid in some commercial pharmaceutical formulations.

\begin{tabular}{lll}
\hline $\begin{array}{c}\text { Pharmaceutical } \\
\text { preparations }\end{array}$ & Claimed & Found* (\%R.S.D.) \\
\hline \hline$(1)$ & $5 \mathrm{mg} / \mathrm{tablet}$ & $4.87 \mathrm{mg} / \mathrm{tablet}(1.2 \%)$ \\
$(2)$ & $0.2 \mathrm{mg} / \mathrm{mL}$ & $0.18 \mathrm{mg} / \mathrm{mL}(2.5 \%)$ \\
$(3)$ & $200 \mu \mathrm{g} / \mathrm{tablet}$ & $184 \mu \mathrm{g} / \mathrm{tablet}(1.7 \%)$ \\
$(4)$ & $800 \mu \mathrm{g} / \mathrm{tablet}$ & $795 \mu \mathrm{g} / \mathrm{tablet}(1.3 \%)$ \\
\hline
\end{tabular}

* Average of two replicate per sample

The results produced by analysing folic acid tablets by differential pulse adsorptive stripping method developed were compared with those obtained by HPLC [57]. This comparison is showed in Table 4. According to these data, both method produce comparable results (reproducibility and relative standard deviation for four injections of standards).

Table 4. Comparison between the results obtained for the differential pulse adsorptive stripping voltammetric and those of HPLC (mean values of four determinations)

\begin{tabular}{llll||lll}
\hline \multicolumn{3}{c||}{$\begin{array}{l}\text { Voltammetric } \\
\text { method }\end{array}$} & \multicolumn{2}{c}{$\begin{array}{l}\text { HPLC } \\
\text { method }\end{array}$} \\
\hline \hline Vitamin & $\begin{array}{l}\text { Mean } \\
\text { content(mg) }\end{array}$ & S.D.(mg) & R.S.D.(\%) & $\begin{array}{l}\text { Mean } \\
\text { content(mg) }\end{array}$ & S.D.(mg) & R.S.D.(\%) \\
\hline $\begin{array}{l}\text { Folic } \\
\text { acid }\end{array}$ & 5.0 & 0.09 & 1.2 & 5.0 & 0.09 & 1.2 \\
\hline
\end{tabular}




\section{CONCLUSIONS}

The use of $\mathrm{KH}_{2} \mathrm{PO}_{4} / \mathrm{NaOH}$ buffer $(\mathrm{pH}=7.1)$ as electrolyte provided a sensitive and selective adsorptive stripping voltammetric method for the folic acid determination. This new method proposed is remarkably insensitive to the presence of commonly interfering substances (e.g., metals and vitamins). In addition, the two-electron reduction obtained in this work ( at $\mathrm{pH}=7.1$ ) for the principal reaction is in agreement with the reaction mechanism of folic acid obtained by Le Gall and van den Berg (at $\mathrm{pH}=5.2$; [52]). In four pharmaceutical preparations, including multivitamins, preliminary results show a good correlation between the amounts of folic acid found by new method proposed with those found by HPLC. In particular, this approach offers as advantage the possible determination of folic acid in presence of ascorbic acid. Further studies on the electroanalytical chemistry of folic acid, folates, and its derivatives using bismuth film are under way.

\section{ACKNOWLEDGEMENTS}

The authors gratefully acknowledge the CNPq and CAPES of the Brazilian Research Councils, PUC-Rio and FIOCRUZ/INCQS for supporting this work.

\section{REFERENCES}

[1] T. Brody, B. Shane, and E.L.R. Stokstad, In Machlin, L.J. (Ed.). Handbook of Vitamins: Nutritional, Biochemical, and Clinical Aspects (New York: Marcel Dekker, 1984, p. 459).

[2] P.A. Mayes, In Murray, R.K., Granner, D.K., Mayes, P.A., and Rodwell, V.W. (Eds.), Harper's Biochemistry. (22 ${ }^{\text {nd }}$ edn., Appleton and Lange, Norwalk, CN, 1990, p. 547).

[3] H.E. Sauberlich, M.J. Kretsch, J.H. Skala, H.L. Johnson, and P.C. Taylor, Folate requirement and metabolism in nonpregnant women, American Journal of Clinical Nutrition, 46 (6), 1987, 10161028 .

[4] D.D.Browning, T. The, and D.H. O'day, Comparative-analysis of chemotaxis in dictyostelium using a radial bioassay method - protein-tyrosine kinase-activity is required for chemotaxis to folate but not to camp, Cellular Signalling, 7(5), 1995, 481-489.

[5] M.H. Hanlon, R. Ferone, K. Weaver, and P. Ray, Enzymatic-synthesis of folate and antifolate polyglutamates with Escherichia-coli folypolyglutamate synthetase, Analytical Biochemistry, 216(2), 1994, 345-351.

[6] C.C. Blanco, A.S. Carretero, A.F. Gutierrez, and M.R. Ceba, Fluorometric-determination of folic-acid based on its reaction with the fluorogenic reagent fluorescamine, Analytical Letters, 27(7), 1994, 1339-1353.

[7] R.A.S. Lapa, J.L.F.C. Lima, B.F. Reis, J.L.M. Santos, and E.A. Zagatto, Photochemical-fluorimetric determination of folic acid in a multicommutated flow system, Analytica Chimica Acta, 351(1-3), $1997,223-228$.

[8] X. Liu, and H. U. Huang, Fluorimetric determination of folic acid in tablets using potassium permanganate as oxidant, Chinese Journal of Analytical Chemistry,28(11), 2000, 1406-1409.

[9] X. Liu, and H.G. Huang, Fluorimetric-determination of folic acid in tablets using hydrogen peroxide as oxidant, Chinese Journal of Analytical Chemistry, 30(8), 2002, 1018-1018.

[10] C.B. Huang, H.W. Chen, and Q.H. He, Flow injection on-line photochemically spectrofluorimetric determination of folic acid in pharmaceutical preparations, Chinese Journal of Analytical Chemistry, 31(2), 2003, 229-231.

[11] P. Anastasopoulos, T. Mellos, M. Spinou, T. Tsiaka, and M. Timotheou-Potamia, Chemiluminometric and fluorimetric determination of folic acid, Analytical Letters, 40(11), 2007, 2203-2216.

[12] J.L. Manzoori, A. Jouyban, M. Amjadi, and J. Soleymani, Spectrofluorimetric determination of folic acid in tablets and urine samples using 1,10-phenanthroline-terbium probe, Luminescence, 26(2), 2011, 106-111.

[13] D. Luo, and J. Wang, A sono-oxidation fluorescence method and determination of folic acid in pharmaceutical formulation, Oxidation Communications, 34 (3), 2011, 675-683.

[14] A.F. Moussa, New colorimetric method for determination of folic-acid in some pharmaceutical preparations, Pharmazie, 33(8), 1978, 542-543.

[15] F. Buhl, and U. Hachula, Spectrophotometric determination of folic-acid and other reductants using coupled redox-complexation reaction with Ce(IV) and arsenazo-III, Chemia Analityczna, 36(1), 1991, 27-34. 
[16] P. Nagaraja, R.A. Vasantha, and H.S. Yathirajan, Spectrophotometric determination of folic acid in pharmaceutical preparations by coupling reactions with iminodibenzyl or 3-aminophenol or sodium molybdate-pyrocatechol, Analytical Biochemistry, 307(2), 2002, 316-321.

[17] C. Paveenbampen, D. Lamontanaro, J. Moody, J. Zarembo, and C. Rehm, Liquid-chromatographic determination of folic-acid in multivitamin preparations, Journal of Pharmaceutical Sciences, 75(12), 1986, 1192-1194.

[18] H. Iwase, Determination of folic-acid in an elemental diet by high-performance liquidchromatography with UV detection, Journal of Chromatography, 609(1-2), 1992, 399-401.

[19] M.J. Akhtar, M.A.Khan, and I. Ahmad, High performance liquid chromatographic determination of folic acid and its photodegradation products in the presence of riboflavin, Journal of Pharmaceutical and Biomedical Analysis, 16(1), 1997, 95-99.

[20] P. Stokes, and K. Webb, Analysis of some folate monoglutamates by high-performance liquid chromatography-mass spectrometry, I. Journal of Chromatography A, 864(1), 1999, 59-67.

[21] M.A. Kall, P. Nørgaard, S.J. Pedersen, and T. Leth, Optimised extraction of folic acid from multivitamin-mineral preparations for liquid chromatographic analysis, Journal of Pharmaceutical and Biomedical Analysis, 23(2-3), 2000, 437-445.

[22] D.E. Breithaupt, Determination of folic acid by ion-pair RP-HPLC in vitamin-fortified fruit juices after solid-phase extraction. Food Chemistry, 74(4), 2001, 521-525.

[23] M.S. Aurora-Prado, C.A. Silva, M.E. Tavares, and K.D. Altria, Determination of folic acid in tablets by microemulsion electrokinetic chromatography, Journal of Chromatography A, 1051(1-2), 2004, 291-296.

[24] B.C. Nelson, K.E. Sharpless, and L.C. Sander, Quantitative determination of folic acid in multivitamin/multielement tablets using liquid chromatography/tandem mass spectrometry, Journal of Chromatography A, 1135(2), 2006, 203-211.

[25] A. Lebiedzinska, M. Dabrowska, P. Szefer, and M. Marszall, High-performance liquid chromatography method for the determination of folic acid in fortified food products, Toxicology mechanisms and methods, 18(6), 2008, 463-467.

[26] S.L. Zhao, H.Y. Yuan, C. Xie, and D. Xiao, Determination of folic acid by capillary electrophoresis with chemiluminescence detection, Journal of Chromatography A, 1107(1-2), 2006, 290-293.

[27] B.T. Zhang, L.X. Zhao, and J.M. Lin, Determination of folic acid by chemiluminescence based on peroxomonosulfate-cobalt(II) system, Talanta, 74(5), 2008, 1154-1159.

[28] Z. Shi-Hao, Z. Ping-Ping, and Z. Shi-Bin, Determination of folic acid by solid-phase extraction and flow injection chemiluminescence, Asian Journal of Chemistry, 22(10), 2010, 7557-7562.

[29] R.H. Huang, A phosphorimetric method for determination of folic acid, Chinese Journal of Analytical Chemistry, 29(3), 2001, 317-319.

[30] W. Wang, and W.D. Sun, Indirect determination of folic acid by inductively coupled plasma-atomic emission spectroscopy, Chinese Journal of Analytical Chemistry, 31(10), 2003, 1280-1280.

[31] L. Rozanski, Polarographic-determination of folic-acid in tablets containing iron(II) sulfate, Analyst, 103(1230), 1978, 950-954.

[32] T.J. Oshea, A.C.Garcia, P.T. Blanco, and M.R.Smyth, Electrochemical pretreatment of carbon-fiber microelectrodes for the determination of folic-acid, Journal of Electroanalytical Chemistry, 307(1-2), 1991, 63-71.

[33] S. Cakir, I. Atayman, and O. Cakir, Simultaneous square-wave voltammetric determination of riboflavin and folic acid in pharmaceutical preparations, Microchimica Acta, 126(3-4), 1997, 237240.

[34] C.F. Watanabe, J. Nozaki, and E.M. Nogami, Differential pulse polarographic determination of folic acid in mushrooms and pharmaceutical tablets, Anales De La Asociation Quimica Argentina, 87(1-2), 1999, 31-35.

[35] C.H. Wang, C.Y. Li, L. Ting, X.L. Xu, and C.F. Wang, Application of a single-wall carbon nano-tube film electrode to the determination of trace amounts of folic acid, Microchimica Acta, 152(3-4), 2006, 233-238.

[36] S.H. Wei, F.Q. Zhao, Z.Y. Xu, and B.Z. Zeng, Voltammetric determination of folic acid with a multiwalled carbon nanotube-modified gold electrode, Microchimica Acta, 152(3-4), 2006, 285-290. 
[37] F. Xiao, C.P. Ruan, L.H. Liu, R. Yan, F.Q. Zhao, and B.Z. Zeng, Single-walled carbon nanotubeionic liquid paste electrode for the sensitive voltammetric determination of folic acid, Sensors and Actuators B-Chemical, 134 (2), 2008, 895-901.

[38] X.L. Jiang, R. Li, J. Li, and X.Y. He, Electrochemical behavior and analytical determination of folic acid on carbon nanotube modified electrode, Russian Journal of Electrochemistry, 45(7), 2009, $772-$ 777.

[39] M. Alireza, and B. Hadi, Electrochemical and catalytic investigations of levodopa and folic acid by modified carbon nanotube paste electrode, Analytical Methods, 3(11), 2011, 2562-2567.

[40] U. Binesh, Y. Yan-Ling, and C. Shen-Ming, Amperometric determination of folic acid at multiwalled carbon nanotube-polyvinyl sulfonic acid composite film modified glassy carbon electrode, International Journal of Electrochemical Science, 6(8), 2011, 3224-3237.

[41] B. Lenka, and S. Renata, Voltammetric determination of folic acid using liquid mercury free silver amalgam electrode, Acta Chimica Slovenica, 58 (4), 2011, 776-784.

[42] A. Taherkhani, H. Karimi-Maleh, A.A. Ensafi, H. Beitollahi, A. Hosseini, M.A. Khalilzadeh, and H. Bagheri, Simultaneous determination of cysteamine and folic acid in pharmaceutical and biological samples using modified multiwall carbon nanotube paste electrode, Chinese Chemical Letters, 23 (2), 2012, 237-240.

[43] S. Kwee, Electrochemistry of the $\mathrm{C}(9)-\mathrm{N}(10)$ bond in folic-acid and related-compounds. Bioelectrochemistry and Bioenergetics, 11(4-6), 1983, 467-475.

[44] D.B. Luo, Determination of folic-acid by adsorptive stripping voltammetry at the static mercury drop electrode, Analytica Chimica Acta, 189(2), 1986, 277-283.

[45] J.M. Fernandez-Alvarez, A. Costa-Garcia, A.J.M. Ordieres, and P. Tunon-Blanco, Adsorptive stripping voltammetric behavior of folic-acid. Journal of Electroanalytical Chemistry, 225(1-2), 1987, 241-253.

[46] N.A. Elmaali, J.C. Vire, G.J. Patriarche, and M.A. Ghandour, Cathodic adsorptive stripping squarewave voltammetry of folic-acid (vitamin-B9), Analusis, 17(4), 1989, 213-216.

[47] J.A. Delpozo, A.C. Garcia, A.J.M. Ordieres, and P.T. Blanco, Phase-selective alternationg-current adsorptive stripping voltammetry of folic-acid on a mercury thin-film electrode. Electroanalysis, 4(1), 1992, 87-92.

[48] M.J.F.Villamil, A.J.M. Ordieres, A.C. Garcia, and P.T. Blanco, Simultaneous adsorptive stripping voltammetric determination of riboflavin and folic-acid in multivitamin preparations, Analytica Chimica Acta, 273(1-2), 1993, 377-382.

[49] W. Szczepaniak, and M. Ren, Adsorptive stripping voltammetric determination of folic-acid in pharmaceutical preparations. Electroanalysis, 6(5-6), 1994, 505-507.

[50] V.D. Vaze, and A.K. Srivastava, Electrochemical behavior of folic acid at calixarene based chemically modified electrodes and its determination by adsorptive stripping voltammetry, Electrochimica Acta, 53(4), 2007, 1713-1721.

[51] M. Korolczuk, and K. Tyszczuk, Determination of folic acid by adsorptive stripping voltammetry at a lead film electrode, Electroanalysis, 19(18), 2007, 1959-1962.

[52] A. -C Le Gall, and C.M.G. van den Berg, Determination of folic-acid in sea-water using adsorptive cathodic stripping voltammetry, Analytica Chimica Acta, 282(3), 1993, 459-470.

[53] J. Wang, J.S. Mahmoud, and P.A.M. Farias, Determination of cardiac-glycosides by adsorptive stripping voltammetry, Analyst, 110(7), 1985, 855-859.

[54] J. Wang, P.A.M. Farias, and J.S. Mahmoud, Measurements of low concentrations of diltiazem by adsorptive stripping voltammetry and flow amperometry, Analyst, 111(7), 1986, 837-839.

[55] C.E. Cardoso, P.A.M. Farias, R.O.R. Martins, and R.Q. Aucelio, Square-wave and differential-pulse adsorptive stripping voltammetry for ultra-trace determination of the anti-angiogenic drug thalidomide in the presence of concomitant drugs, Analytical Letters, 38(8), 2005,1259-1274.

[56] E. Laviron, Adsorption, autoinhibition, autoinhibion and autocatalysis in polarography and in linear potential sweep voltammetry, Journal of Electroanalytical Chemistry, 52(3), 1974, 355-393.

[57] USP, United States Pharmacopeial Convention, INC. U.S. Pharmacopeia Nacional Farmulary. (24 ed., Washington, D.C., Nacional Publishing Philadelphia, PA., 2000, p.753). 